\title{
Urinary Helicobacter pylori infection: An Expanding Horizon
}

\section{Mohammed S. Al-Marhoon}

Urology Division, Department of Surgery, College of Medicine \& Health Sciences, Sultan Qaboos University, P.O. Box 35, Al-Khoud 123, Oman

\section{Abstract}

What is Helicobacter pylori (H. pylori) and do we need to know about it as urologists. H. pylori infection is a focus of attention nowadays. It has been found to cause gastrointestinal disorders [1], and extraintestinal disorders [2]. The aim of this mini-review is to highlight the ongoing research addressing the question of whither $H$. pylori has a role to play in urological diseases, especially prostate and bladder cancers. Current studies have paved the way for further comprehensive studies to examine the association of $H$. pylori infection with BPH and prostate cancer. If $H$. pylori is found to have a significant role in urological diseases, prevention of bladder and prostate cancers by eradication of $H$. pylori infection may become a reality like what happened in the treatment of peptic ulcer disease and gastric cancer.

\section{Publication History:}

Received: August 17, 2017

Accepted: October 09, 2017

Published: October 11, 2017

\section{Keywords:}

Helicobacter pylori, Urological diseases, Gastric cancer

\section{Introduction}

The spiral shaped bacterium $H$. pylori is strongly associated with inflammation of the stomach and is also implicated in the development of gastric malignancy. H. pylori is associated with peptic ulcers and chronic gastritis in humans. It is associated with duodenal ulcers and has been associated with the development of adenocarcimona and low grade lymphoma of mucosa associated lymphoid tissue in the stomach. More recently this bacterium has also been associated with urinary infections. Karatas et al. [3] in a pilot study reported that, seropositivity for antibody against $H$. pylori was significantly higher in the chronic prostatitis/chronic pelvic pain syndrome (CP/CPPS) than the control group and supports the hypothesis that H. pylori may play a role in CP/CPPS. In addition, Cheng et al. [4] in a prospective study found that, men having a history of prostatitis had an increased risk of prostate cancer than men with no history $(\mathrm{RR}=1.30$; $95 \% \mathrm{CI}: 1.10$ 1.54 ) and suggested that prostatitis may be involved in prostate cancer susceptibility. It is not clear how $H$. pylori is transmitted or why some patients become symptomatic while others do not. The bacteria are most likely spread from person to person through fecal to oral or oral to oral routes. Possible environmental sources include contaminated water reservoirs. H. pylori can exist in a number of locations: in the mucus; attached to epithelial cells; or inside of vacuoles in epithelial cells, where it produces adhesions that bind to membrane-associated lipids and carbohydrates in or on epithelial cells. Diagnosis of H. pylori is usually made by checking for dyspeptic symptoms and by tests which can indicate $H$. pylori infection. One can test noninvasively for H. pylori infection with a blood antibody test, stool antigen test, or with the carbon urea breath test (in which the patient drinks $14 \mathrm{C}$ or 13C-labelled urea, which the bacterium metabolizes, producing labeled carbon dioxide that can be detected in the breath). However, the most reliable method for detecting $H$. pylori infection is a biopsy during endoscopy with a rapid urease test, histologic examination, and microbial culture.

It has been demonstrated that the prostate does not harbor normal bacterial flora by the absence of bacterial genomes in histologically normal prostates. The etiology of the chronic prostatitis/pelvic pain syndrome remains controversial, some believing that bacteria are present but do not appear on conventional aerobic cultures. A molecular technique to detect bacteria that do not grow in culture is to use PCR (Polymerase Chain Reaction) for bacterial 16S rDNA. Bacterial DNA sequences were found to be present in prostate biopsy specimens in $77 \%$ of men with chronic prostatitis/pelvic pain syndrome. Also $78 \%$ of prostatectomy specimens from men who had prostate cancer or BPH (benign prostate hyperplasia) were positive for bacterial DNA.

\section{Proposed mechanism of oncogensis induced by $H$. pylori}

The rationale of proposing a relation for $H$. pylori to bladder and prostate diseases are based on the following observations: $H$. pylori has been detected in other organs and correlates with other cancers. It has long been known that certain infectious agents that affect specific areas of the body can also have systemic sequelae. $H$. pylori infection is a triggering factor in the process of increasingly severe inflammation progressing from chronic active inflammation to atrophy, metasplasia, dysplasia and cancer. It was shown in a mouse model of chronic bacterial prostatitis induced by Escherichia coli that chronic inflammation leads to severe dysplasia and atypical hyperplasia in the prostate. Epidemiological studies show significant associations between infection and prostatic carcinoma. Also $78 \%$ of prostatectomy specimens from men who had prostate cancer or $\mathrm{BPH}$ were positive for bacterial DNA, It has been reported that MALT lymphoma of the urinary bladder disappeared after treatment with H. pylori eradication therapy. H. pylori was transurethrally inoculated into the mouse urinary tract, the organism established infection and induced inflammation in the urinary bladder and pelvis.

\section{H. pylori related ongoing research}

The possibility that a bacterium could cause gastritis, peptic ulcers and cancer was a difficult concept to accept, especially as it would change the whole concept of the pathophysiology of ulcer disease that was based on acid etiology. It is now clear that infection with $H$. pylori is associated with peptic ulcer disease and gastric cancer. H. pylori has been designated a group one (definitive) carcinogen by the World Health Organization. The pathways by which $H$. pylori leads to gastric cancer have been shown by models of gastric carcinogenesis. Correa's multi-step model showed that $H$. pylori infection is a triggering factor in the process of increasingly severe gastric lesions progressing from chronic active gastritis to atrophy, intestinal metasplasia, dysplasia and gastric cancer. Al-Marhoon [5] proposed a model

"Corresponding Author: Dr. Mohammed S. Al-Marhoon, Urology Division, Department of Surgery, College of Medicine \& Health Sciences, Sultan Qaboos University, P.O. Box 35, Al-Khoud 123, Sultanate of Omanl; Email: msalmarhoon@gmail.com

Citation: Al-Marhoon MS (2017) Urinary Helicobacter pylori infection: An Expanding Horizon. Int J Surgical Porced 2: 125. https://doi.org/10.15344/2456$4443 / 2017 / 125$

Copyright: (c) 2017 A-Marhoon. This is an open-access article distributed under the terms of the Creative Commons Attribution License, which permits unrestricted use, distribution, and reproduction in any medium, provided the original author and source are credited. 
indicating the initial changes induced by $H$. pylori infection that play a role in protecting the organism and enhancing its colonization in the stomach that may lead to gastric cancer. In addition, Al-Marhoon [6] reviewed the literature about $H$. pylori and its relation to urological disorders, and found an accumulating evidence appearing in the literature relating $H$. pylori infection to urological diseases. The most obvious is the implication of $H$. pylori in inducing chronic cystitis leading to bladder lymphoma. [7] In addition, some epidemiological studies have shown significant associations between infective chronic prostatitis and prostatic carcinoma. [8] Recently, Al-Marhoon [9] have conducted a study to determine whether $H$. pylori is detectable in both benign prostatic hyperplasia $(\mathrm{BPH})$ and prostate cancer $(\mathrm{PCa})$ by studying 100 consecutive patients with prostate diseases. Detection of $H$. pylori DNA in prostate tissue from patients with $\mathrm{BPH}$ and $\mathrm{PCa}$ was performed using both immunohistochemistry and PCR, and the results were confirmed by DNA sequencing. In this study, $78 \%$ of patients had BPH and 19\% had PCa. While immunohistochemistry showed no positive sample for $H$. pylori, PCR combined with sequencing detected $H$. pylori DNA in prostate tissue samples from 5 patients. However, statistical analysis of the data showed that $\mathrm{BPH}$ and PCa are not significantly associated with the presence of $H$. pylori DNA in prostate tissue (odds ratio $=0.94,95 \%$ con dence interval $=0.09-23.34$, one-tailed Chi-square value $=0.660, \mathrm{p}>0.05)$. The limitation of this study was the small number of PCa patients. This study provided, for the first time, molecular evidence of the presence of $H$. pylori DNA in prostatic tissue of patients with $\mathrm{BPH}$ and $\mathrm{PCa}$.

\section{Conclusion}

Current studies have paved the way for further comprehensive studies to examine the association of $H$. pylori infection with $\mathrm{BPH}$ and PCa. If $H$. pylori is found to have a significant role in urological diseases, prevention of bladder and prostate cancers by eradication of $H$. pylori infection may become a reality like what happened in the treatment of peptic ulcer disease and gastric cancer.

\section{Competing Interests}

The authors declare that they have no competing interests.

\section{References}

1. D Forman, D G Newell, F Fullerton, J W Yarnell, A R Stacey et al. (1991) Association between infection with Helicobacter pylori and risk of gastric cancer: evidence from a prospective investigation. BMJ 302:1302-5.

2. P. Patel, M. A. Mendall, D. Carrington, D. P. Strachan, E. Leatham et al (1995) Association of Helicobacter pylori and Chlamydia pneumoniae infections with coronary heart disease and cardiovascular risk factors. BMJ 311:711-4.

3. Karatas OF, Turkay C, Bayrak O, Cimentepe E, Unal D. (2010) Helicobacter pylori seroprevalence in patients with chronic prostatitis: a pilot study. Scand.J Urol Nephrol 44:91-4.

4. Cheng I, Witte JS, Jacobsen SJ, Haque R, Quinn VP et al. (2010) Prostatitis sexually transmitted diseases, and prostate cancer: the California Men's Health Study. PLoS.One. 5:e8736.

5. Al-Marhoon MS, Nunn S, Soames RW. (2004) The association between cagA + H. pylori infection and distal gastric cancer: a proposed model. Dig. Dis.Sci. 49:1116-22.

6. Al-Marhoon MS. (2008) Is there a role for Helicobacter pylori infection in urological diseases? Urol J 5:139-43.

7. Bayerdörffer E, Neubauer A, Rudolph B, Thiede C, Lehn N et al. (1995) Regression of primary gastric lymphoma of mucosa-associated lymphoid tissue type after cure of Helicobacter pylori infection. MALT Lymphoma Study Group. Lancet 345:1591-4.
8. Dennis LK, Lynch CF, Torner JC. (2002) Epidemiologic association between prostatitis and prostate cancer. Urology 60:78-83.

9. Al-Marhoon MS, Ouhtit A, Al-Abri AO, Venkiteswaran KP, Al-Busaidi $Q$ et al.(2014) Molecular evidence of Helicobacter Pylori infection in prostate tumors. Current Urology 8: 138-143. 